\title{
Is there a relationship between socio-economic factors and biodiversity in urban ponds? A study in the city of Stockholm
}

\author{
Malgorzata Blicharska ${ }^{1,2}$. Johan Andersson ${ }^{3}$. Johannes Bergsten ${ }^{4}$ - Ulf Bjelke ${ }^{5}$. \\ Tuija Hilding-Rydevik ${ }^{1} \cdot$ Michaela Thomsson $^{6} \cdot$ John $_{\text {Östh }}{ }^{6} \cdot$ Frank Johansson $^{3}$
}

Published online: 21 April 2017

(C) The Author(s) 2017. This article is an open access publication

\begin{abstract}
Urban small water bodies, such as ponds, are essential elements of human socio-economic landscapes. Ponds also provide important habitats for species that would otherwise not survive in the urban environment. Knowledge on the biodiversity of urban ponds and the relationship between their ecological value and factors linked to urbanization and socio-economic status is crucial for decisions on where and how to establish and manage ponds in cities to deliver maximum biodiversity benefits. Our study investigates if the pattern of urban-pond biodiversity can be related to different socio-economic factors, such as level of wealth, education or percentage of buildings of different types. Because of lack of previous studies investigating that, our study is of exploratory character and many different variables are used. We found that
\end{abstract}

Electronic supplementary material The online version of this article (doi:10.1007/s11252-017-0673-2) contains supplementary material, which is available to authorized users.

Malgorzata Blicharska

malgorzata.blicharska@geo.uu.se

1 Swedish Biodiversity Centre, Swedish University of Agricultural Sciences, Box 7016, 75007 Uppsala, Sweden

2 Natural Resources and Sustainable Development, Department of Earth Sciences, Uppsala University, Villavägen 16, 75

236 Uppsala, Sweden

3 Department of Ecology and Genetics, Uppsala University, Norbyvägen 18D, 75236 Uppsala, Sweden

4 Department of Zoology, Swedish Museum of Natural History, Box 50007, SE-10405 Stockholm, Sweden

5 The Swedish Species Information Centre, Box 7007, SE-750 07 Uppsala, Sweden

6 Department of Social and Economic Geography, Uppsala University, Box 513, SE-751 20 Uppsala, Sweden the biodiversity of aquatic insects was significantly negatively associated with urbanisation variables such as amount of buildings and number of residents living around ponds. This relationship did not differ depending on the spatial scale of our investigation. In contrast, we did not find a significant relationship with variables representing socio-economic status, such as education level and wealth of people. This latter result suggests that the socio-economic status of residents does not lead to any particular effect in terms of the management and function of ponds that would affect biodiversity. However, there is a need for a finer-scale investigation of the different potential mechanism in which residents in areas with differing socio-economic status could indirectly influence ponds.

Keywords Biodiversity · Socio-economic factors ·

Urbanization $\cdot$ Urban ponds $\cdot$ Stockholm

\section{Introduction}

Urban small water bodies, such as ponds, are essential elements of human socio-economic landscapes. They also provide important habitats for species that would otherwise not survive in the urban environment (Colding et al. 2009; Hill and Wood 2014; O'Brien 2015). While ponds in rural landscapes have been well investigated (Biggs et al. 2005; Céréghino et al. 2008; Davies et al. 2008), there are far fewer studies about the biodiversity of these environments located in cities. Studies that consider ponds in cities have tended to concentrate on ponds in urban gardens (Gaston et al. 2004, 2005; Loram et al. 2011), but many ponds can also be found in the overall urban landscape, particularly within green areas, such as parks or nature conservation areas (Gledhill et al. 2005; Gledhill and James 2012; Blicharska et al. 2016). 
Urban ponds have been found to have high natural value and rich biodiversity (Le Viol et al. 2009; Hassall and Anderson 2015). However, there is little knowledge on the relationship between urbanisation factors such as spatial configuration and socio-economic factors and the ecological value of urban ponds. Such knowledge could be very important when planning urban areas, as it could inform planning decisions that would benefit both people and biodiversity. For example, knowledge on species richness in the ponds could provide rationale for creation of new ponds or preventing filling the existing ones, and information on which variables are associated with high richness could facilitate better selection of areas for establishing new ponds, as well as improved management measures at local level. The current trend of increasing urbanisation necessitates the effective management of existing green and blue areas in urban landscapes to assure that they deliver maximum benefits, both in terms of biodiversity and human well-being. Hence green and blue areas are designed to both provide habitats for different species, and to be attractive for the people living in the proximity. Understanding how different socio-economic variables can potentially be related to the biodiversity of ponds would be helpful, as it could provide information on where, how and why to establish new ponds. In addition, studies have shown that walking, watching or in other ways being close to water bodies and biodiverse resources such as ponds are positive for physical and psychological wellbeing (Johansson et al. 2011; Blicharska and Johansson 2016) indicating that planners need to take both human wellbeing and biodiversity into account.

Different studies have explored the role of people in shaping the natural environment in cities, particularly focusing on vegetation distribution (Martin et al. 2004; Grove et al. 2006; Luck et al. 2009; Locke and Grove 2016), and diversity of avian species (Kinzig et al. 2005; Melles 2005). These studies are often rooted in the human population density, behavioural or social stratification theories that link diversity or distribution of species to either population and housing density (Smith et al. 2005), or different social strata existing in the societies (Hope et al. 2003; Tratalos et al. 2007; Locke and Grove 2016) or lifestyle behaviour associated with perceived norms (Troy et al. 2007; Nassauer et al. 2009), linked to e.g. "luxury" and "legacy" effects (Martin et al. 2004; Cook et al. 2012). The described mechanisms, associated with socio-economic status of people, are said to influence both formal and informal practices that shape urban environments (Locke and Grove 2016). For example, lifestyle choices and linked management activities by urban residents can be influenced by the desire to conform to the (often informal) rules represented by particular social group (Grove et al. 2006), so called "ecology of prestige" (Troy et al. 2007). Also, management practices can vary depending on personal ideals and attributes, knowledge level or possibilities linked to income level (Cook et al. 2012).
Although the theories and studies described above are derived from investigations of vegetation and birds in cities, building on them one could expect that also biodiversity of urban waters could potentially depend on the influences of humans. Luxury or legacy effects could, for example, have consequences for ponds' biodiversity, as they in general shape how the neighbourhoods look like and how they are taken care of (Martin et al. 2004). The level of management in and around ponds could be linked to the affluence of the residents, as more wealthy residents have more possibilities to influence their surrounding environment (Landry and Chakraborty 2009) and also have simply larger potential to move to more attractive cared-for areas (Fischel 1985). For example, it is possible that in low income areas the city planners and managers of green areas do not put that much effort in the management of these areas as they would do in more wealthy neighbourhoods, which could have some influence on biodiversity. On the other hand developments in more affluent areas could potentially lead to unnatural and barren habitat not beneficial for biodiversity as well. For example, it has been shown that impervious surfaces (e.g. car parking areas) may take over the green areas in more affluent places (Perry and Nawaz 2008). However, to the best of our knowledge, there has been almost no studies that would attempt to investigate these potential relations. One study by Gledhill and James (2012) has attempted to explore the relationship between the ecological status of urban ponds and socio-economic variables. The authors looked at the ponds in two towns in northwest England and explored the potential correlation of their ecological status with both socio-economic factors and landscape features. According to their results, neither social classification of particular local areas nor house prices determined the species richness of ponds. However, the social character of particular areas significantly influenced the ponds' Community Conservation Index (CCI: describing species richness, their rarity and pollution tolerance). The highest CCI was scored for ponds located in areas classified as "Constrained by circumstances", which the authors suggested may be related to an increased amount of green spaces in such areas. These authors also found that Biological Monitoring Working Party statistics (indicating tolerance to organic pollutants by a ponds' species) decreased with increasing house prices (i.e. an index for assessing socio-economic conditions of particular areas), which they suggested may be related to variation in management activities, increased use of cars, and paving of front gardens for parking in more affluent areas. Another study, by Blicharska et al. (2016) investigated if pond function and level of management influenced pond biodiversity. They found no significant relationship between these variables, but revealed that biodiversity in ponds were correlated with amount of vegetation in water, which could be indirectly linked to management. Still, it is clear that more studies of urban ponds are needed in order to establish firmer 
conclusions on the relationships between socio-economic factors and urban pond biodiversity and our study attempts to contribute to fill parts of this research gap. However, because of little existing information on the potential mechanisms that could influence urban pond biodiversity, the study is of exploratory character, where many different variables are tested.

The aim of the present study was to investigate if the pattern of urban-pond biodiversity, is related to various socio-economic factors. To address this question, we gathered information about the several metrics of biodiversity (species richness, Shannon-Wiener and Evenness) of 51 ponds in the city of Stockholm, Sweden, and related them to the socioeconomic variables given in Table 1. Three different scales were addressed, to see if potential effects of socio-economics may differ with scale.

\section{Methods}

\section{Study area and pond selection}

Our study was conducted in Stockholm. The city has ca. 900,000 residents but the metropolitan area is home to approximately 1.5 million inhabitants and is characterised by a large number of areas of open water and high coverage of green areas (Andersson et al. 2009). In the present study, we considered 51 ponds in central Stockholm, which covers seven municipalities (Fig. 1). We tried to find all ponds in these municipalities by scanning maps and using information from municipalities' officials. We defined ponds as natural or man-made water bodies having an area between $1 \mathrm{~m}^{2}$ and 2 ha and holding water for at least 4 months of the year (Biggs et al. 2005;

Table 1 Variables used in the analysis. SEK = Swedish krona (1 SEK = approximately 0,1 Euro in 2015)

\begin{tabular}{|c|c|c|}
\hline Variable [variable name] & Unit & Explanation \\
\hline Pond size [PondSize] & $\mathrm{m}^{2}$ & Size of the pond \\
\hline Age of buildings [BuldingsAge] & year & Average age of buildings within specified radius around the pond \\
\hline Percentage of detached houses [DetachedPerc] & $\%$ & Percentage of detached houses within specified radius around the pond \\
\hline Percentage of row houses [RowHousePerc] & $\%$ & Percentage of row houses within specified radius around the pond \\
\hline Percentage of apartment blocks [ApartmentPerc] & $\%$ & Percentage of apartment blocks within specified radius around the pond \\
\hline Percentage of other housing [OtherHousPerc] & $\%$ & $\begin{array}{l}\text { Percentage of other types of housing buildings within specified radius around the } \\
\text { pond }\end{array}$ \\
\hline Percentage of community buildings [CommBuildPerc] & $\%$ & Percentage of community buildings within specified radius around the pond \\
\hline Percentage of industry buildings [IndustryBPerc] & $\%$ & Percentage of industry buildings within specified radius around the pond \\
\hline Percentage of other buildings [OtherBuildPerc] & $\%$ & Percentage of other buildings within specified radius around the pond \\
\hline Percentage of lakes [PercLakes] & $\%$ & Percentage of open water or lakes within specified radius around the pond \\
\hline Percentage of all buildings [AllBuildPerc] & $\%$ & Percentage of all buildings together within specified radius around the pond \\
\hline Amount of residents [Residents] & Number & Total number of people within specified radius around the pond \\
\hline Percentage of visible minority [VisMinPerc] & $\%$ & $\begin{array}{l}\text { Percentage of so called "visible minority", a group of people whose country of } \\
\text { birth suggests that they are likely to look like "minority group" and be exposed } \\
\text { to racial discrimination, within specified radius around the pond. The group } \\
\text { included The Americans south of USA, all of Asia (excluding Russia), all of } \\
\text { Africa and Oceania (excluding Australia and New Zea land) }\end{array}$ \\
\hline $\begin{array}{l}\text { Percentage of relatively low educated people } \\
\text { [LowEduPerc] }\end{array}$ & $\%$ & $\begin{array}{l}\text { Percentage of relatively low educated people, based on highest attained education } \\
\text { level within regular school system, within specified radius around the pond. } \\
\text { Relatively low education includes people how have not finished lower } \\
\text { secondary school or have done so, but not started any higher education }\end{array}$ \\
\hline $\begin{array}{l}\text { Percentage of relatively high educated people } \\
\text { [HighEduPerc] }\end{array}$ & $\%$ & $\begin{array}{l}\text { Percentage of relatively high educated people, based on highest attained } \\
\text { education level within regular school system, within specified radius around } \\
\text { the pond. Relatively high education includes people with post-secondary } \\
\text { school education }\end{array}$ \\
\hline Percentage of relatively poor people [RelPoorPerc] & $\%$ & $\begin{array}{l}\text { Percentage of relatively poor people, i.e. people earning less than } 60 \% \text { of the } \\
\text { Swedish national medium income, within specified radius around the pond }\end{array}$ \\
\hline Percentage of relatively rich people [RelRichPerc] & $\%$ & $\begin{array}{l}\text { Percentage of relatively rich people, i.e. people earning } 1.4 \text { times the national } \\
\text { medium income, within specified radius around the pond }\end{array}$ \\
\hline $\begin{array}{l}\text { Percentage of people getting social support } \\
\text { [SocHelpPerc] }\end{array}$ & $\%$ & Percentage of people getting social support, within specified radius around the pond \\
\hline Disposable income [DispIncome] & $100 \mathrm{~s}$ SEK & Average income of all residents within specified radius around the pond \\
\hline Distance to nearest highway [DistHighway] & $\mathrm{m}$ & Distance to nearest highway from pond coordinates \\
\hline Distance to nearest train station [DistTrain] & $\mathrm{m}$ & Distance to nearest train station from pond coordinates \\
\hline
\end{tabular}


Fig. 1 Location of the investigated ponds in the study area in the city of Stockholm, Sweden. Orange sections depict urban areas, grey sections indicate land. Central railway station and highways are indicated to make identification of ponds easier

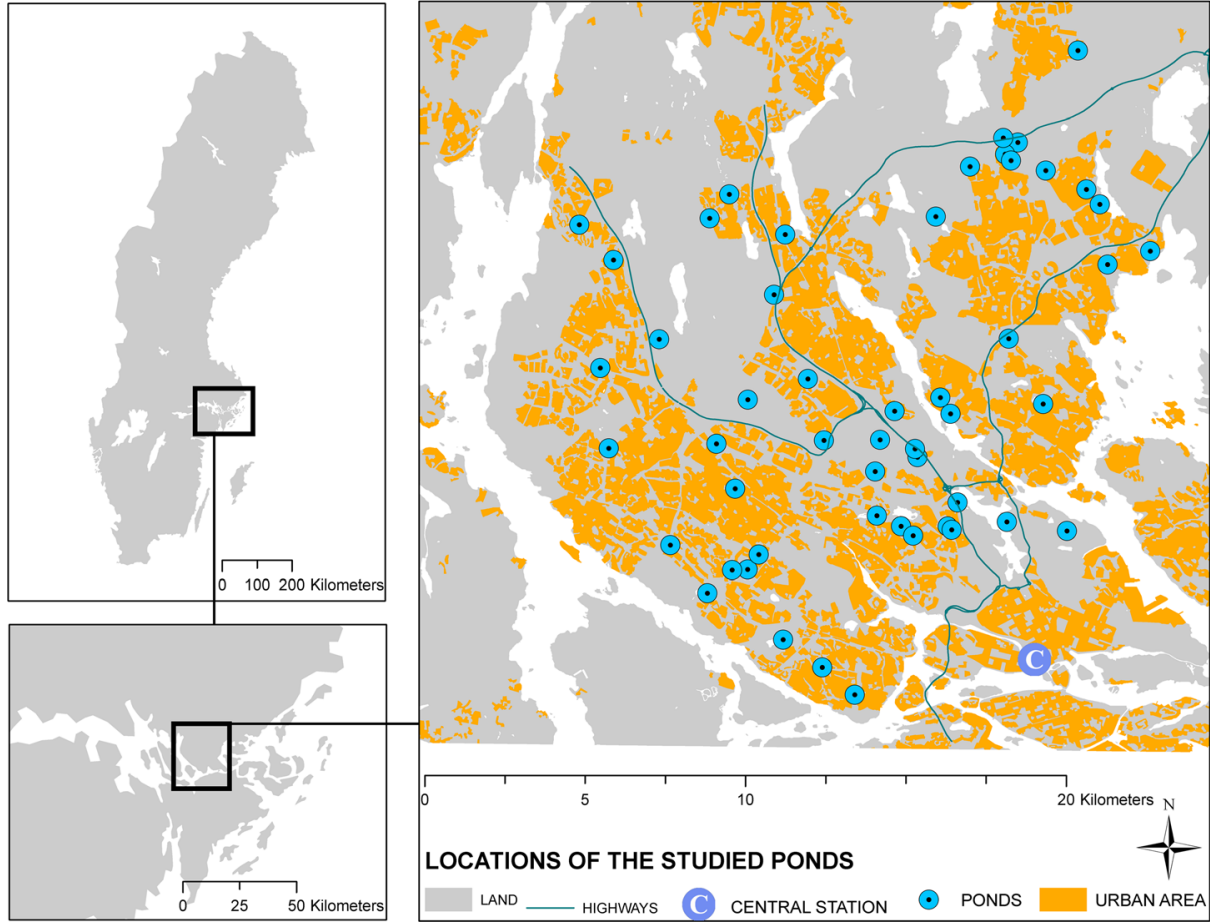

Pond Conservation 2002). The selected ponds ranged in size from 13 to $17.219 \mathrm{~m}^{2}$ (mean $1794 \mathrm{~m}^{3}$ ). We took into account only densely populated areas in the city, i.e. areas where $>75 \%$ of the area (looking at each $1 \times 1 \mathrm{~km}$ square) is developed, as defined by the Swedish mapping, cadastral and land registration authority (Lantmäteriet). This meant that, for example, ponds located in golf courses were excluded, even though they usually have high potential value for biodiversity in urban areas (Colding et al. 2009).

\section{Biodiversity data}

We defined biodiversity in terms of three metrics: species richness, Shannon Wiener diversity and eveness (Krebs 1989) for dragonflies (Odonata), aquatic beetles (Coleoptera), aquatic true bugs (Hemiptera) and caddisflies (Trichoptera). These invertebrates represent various functional groups, and may thus represent overall biodiversity in city ponds (Oertli et al. 2010; Hassall et al. 2011).

Aquatic insects were sampled in May-June 2013 and May-June 2014 with a bottom scoop net with a diameter of $20 \mathrm{~cm}$ and a mesh size of $1.5 \mathrm{~mm}$. We used a sampling strategy derived from the Swedish Environmental Protection Agency's guidelines (SEPA 2006). Six samples were taken in each pond at a depth of $2-3 \mathrm{dm}$. The net was swept along the bottom in opposite directions (left to right) eight times on a $1 \mathrm{~m}$ stretch (one sample). By using six samples, we covered all types of representative microhabitats along the shoreline, e.g. soft bottom, hard bottom, with and without vegetation. We sampled the aquatic life stages i.e. larvae in Odonata and
Trichoptera and larvae and adults in Coleoptera and Hemiptera. We determined the Order of all insects at the pond site and then preserved the specimens in $70 \%$ ethanol, stored them in labelled plastic tubes and brought them back to the laboratory for further identification to species level. All other organisms that did not belong to the selected taxa were immediately released back to their respective ponds. Specimens that could not be determined to species level (in most cases early instar larvae) were ascribed to family or genuslevel and included in the final analysis as separate taxa. These were Odonata larvae of Coenagrion pulchella and $C$. pulchellum that were not distinguishable and were, therefore, regarded as the same species in our analysis. The same applies to three cases among the Trichoptera, where larvae could not be distinguished between pairs of species. These were i) Limnephilus affinis and L. incisus, ii) Limnephilus luridus and L. ignavus and iii) Oligotricha stricta and O. lapponica.

\section{Socio-economic data}

Because of the paucity of studies that would indicate which socio-economic factors could influence biodiversity in urban ponds, our study is of exploratory character and thus we include a large set of variables (Table 1). We chose socioeconomic variables (for details see Table 1) related to the social-economic status of residents, for example, education level (represented by variables: $\%$ of relatively low educated people and $\%$ of relatively high educated people) or wealth (disposable income, $\%$ of relatively poor people and $\%$ of 
relatively rich people, that could potentially be linked to "luxury" or social norms effects. We also selected variables linked to urbanisation, for example, number of residents, percentage of buildings by type that is a proxy for impervious surfaces, indicating less green areas, or age of buildings that can reflect potential legacy effects (Table 1). The socio-economic data were sourced from Statistics Sweden (SCB 2015), compiled at research database, PLACE. The PLACE database contains geocoded $(100 \mathrm{~m} \times 100 \mathrm{~m})$ and individual level statistics of socio-economic and demographic status. In this study, geocoded statistics for the year ending December 2010 were employed. Three buffer zones with a radius of 200, 500 and $800 \mathrm{~m}$ around each pond (from coordinates indicating the middle of the pond) were created and the different variables were constructed as counts within each buffer zone. The socio-economic variables describing the surrounding planned landscape, such as distance to a highway or distance to a train station, were measured in meters from pond coordinates. Finally, we also used size of ponds as one of the potentially explanatory variables, as habitat size is a strong predictor of species richness (MacArthur and Wilson 1967; Oertli et al. 2002; Kadoya et al. 2004). The list of all variables is presented in Table 1. The geographical and statistical context of the ponds included in our study is exemplified in Fig. 2 (for details see Fig. 2 caption).

For some ponds there were no people or buildings within the buffer zones investigated ( 24 ponds for $200 \mathrm{~m}$ radius and 12 ponds for $500 \mathrm{~m}$ ). Thus, no age of buildings or income variables were included in the analysis of the $200 \mathrm{~m}$ and $500 \mathrm{~m}$ buffer zones. Age of buildings and income variables were included in relation to $800 \mathrm{~m}$ buffer zones, although one pond was removed from the analysis as its surrounding lacked both houses and residents within the prescribed radius.

\section{Data analysis}

Our study was of exploratory character, because of little existing knowledge on the potential factors that could influence species richness in urban ponds (see Introduction), and therefore relatively many exploratory variables were used. Some of the variables were correlated (see example of correlation matrix for $500 \mathrm{~m}$ scale in Online Resource 1). For example education was correlated with income and visible minority was correlated with income and education level. We therefore used Principal Component Analysis (PCA) to reduce them to uncorrelated principal components (PCs). The Varimax rotation method with Kaiser Normalization was used to find the simplest structure in the data while explaining as much of the variance as possible. The PCs were extracted based on an Eigenvalue 1. The variables with a factor loading of at least 0.5 were included for interpretation. The resulting PCs were then used in regression analysis to check if any of them were correlated with the three metrics of biodiversity using all taxa: species richness, Shannon-Wiener diversity, and Evenness (J). In addition, we regressed species richness against the PCs' separately for each insect order in order to examine if they showed a taxon specific pattern. All analyses were conducted separately for each size of buffer zone (i.e. 200,500 and $800 \mathrm{~m}$ radius) around every pond, to see if the scale of analysis influenced relationships between biodiversity and socio-economic variables. The analyses were conducted using SPSS software (IBM SPSS Statistics 22).
Fig. 2 Geographical and statistical context of the ponds. In section (a) blocks and houses in each of the blocks and one of the ponds are depicted. From the pond three buffers with the radii distances of $200 \mathrm{~m}, 500 \mathrm{~m}$, and $800 \mathrm{~m}$ are shown in different grey colours in section (b). In section (c), the share of wealthy individuals (relative wealth according to EU definitions) per $100 \mathrm{~m} \times 100 \mathrm{~m}$ is indicated. The gridded $100 \mathrm{~m}$ individual level statistics is the basis for the socioeconomic studies used in our analyses. In section d, the pond's location relative to all other studied ponds in the Northern parts of Stockholm is indicated
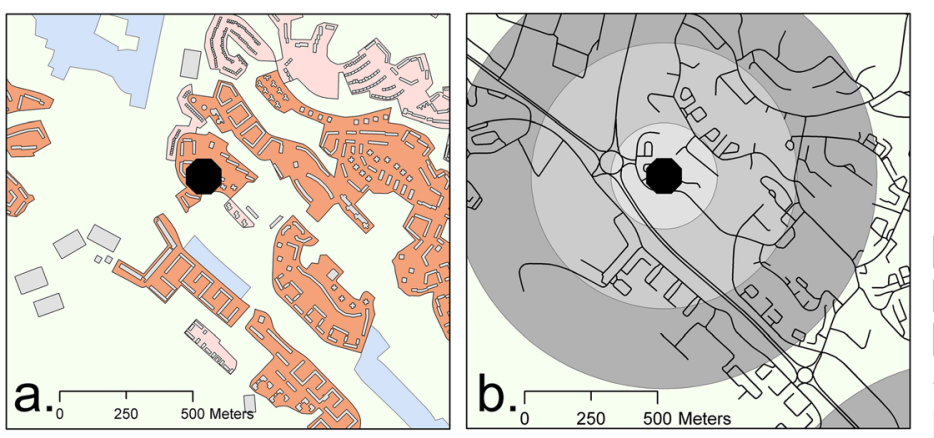

Geographical and Statistical context of ponds
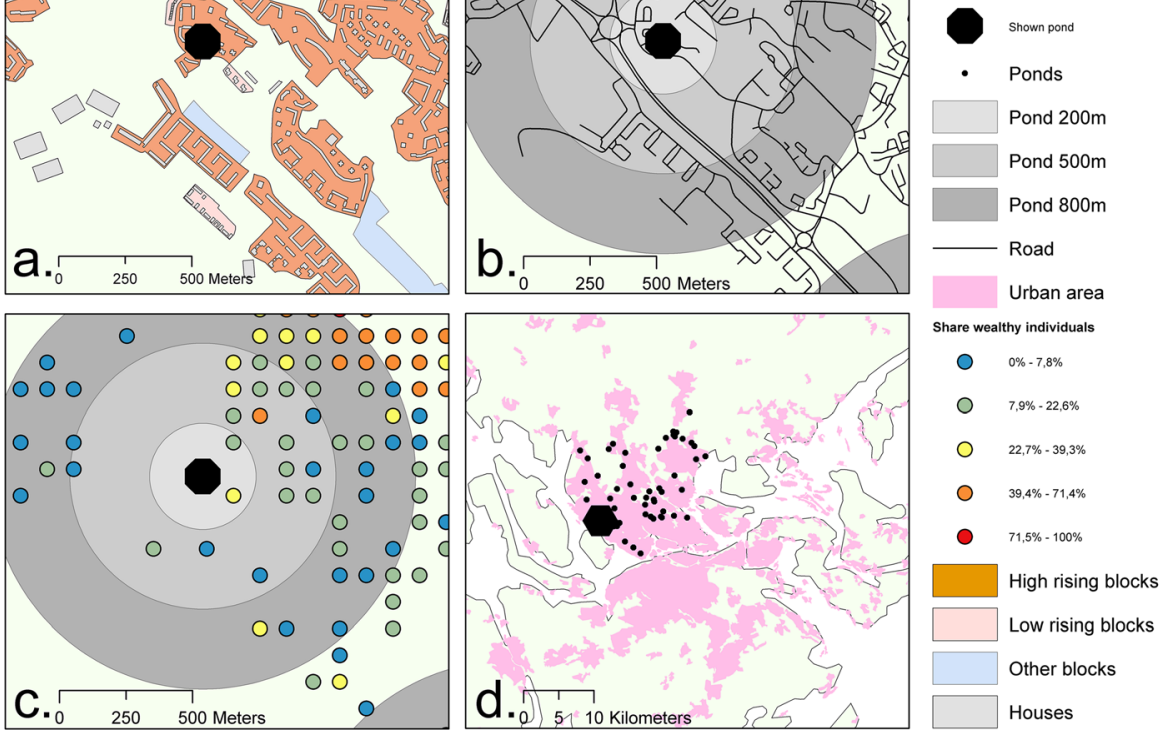


\section{Results}

\section{Correlations between variables}

Principal Component Analysis of correlated variables that had an Eigenvalue $>1$ resulted in seven Principal Components (PCs) for buffer zones of 200 and $500 \mathrm{~m}$ radius, and six PCs for buffer zones of $800 \mathrm{~m}$ radius (Tables 2, 3 and 4). In combination, these PCs explained 71.2, 78.6 and $75.0 \%$ of variance in the data for the 200, 500 and $800 \mathrm{~m}$ buffer zones respectively.

At a 200 m radius:

- PC1 (22\% variance explained) was associated with education, wealth of people, percentage of people getting social help, and distance to highway; the highest positive correlation in this PC was with percentage of people getting social help, while the highest negative correlation was with percentage of relatively high educated people;

- PC2 (13.7\%) was positively associated with low education and percentage of relatively poor people;

- PC3 (8.4\%) was positively associated with per cent of all buildings and number of residents; and

- PC 4 (7.9\%) was positively associated with the percentage of other buildings, and pond size.
The other three PCs (PC5, PC6 and PC7) explained relatively little of the variation (6.9, 6.6 and 5.7\% respectively) and, thus, were not considered in further analysis of relationships between PCs and species richness.

At a 500 m radius:

- PC1 (26.6\% of variance explained) was positively associated with percentage of visible minority, percentage of people getting social help and percentage of relatively low educated and poor people. It was at the same time negatively associated with percentage of relatively high educated and rich people;

- PC2 (14.1\%) was positively associated with number of residents, total percentage of buildings and apartments and community buildings;

- PC3 (11.5\%) was positively associated with percentage of other houses and buildings and distance to train station;

- Finally, PC 4 (8.4\%) was positively associated with percentage of industrial buildings and percentage of relatively low educated.

The remaining PCs (PC 5, 6 and 7) explained relatively little of the variation (7.1, 5.5 and 5.3\% respectively) and, thus, were not included in further analysis.
Table 2 Results of the PCA of the variables for $200 \mathrm{~m}$ radius around the pond. In bold: factor loading at least 0.5

\begin{tabular}{|c|c|c|c|c|c|c|c|}
\hline \multirow[t]{2}{*}{ Variables } & \multicolumn{7}{|c|}{ Components and their interpretation } \\
\hline & $\begin{array}{l}\text { PC } 1 \text { Socio- } \\
\text { economic } \\
\text { status (1) }\end{array}$ & $\begin{array}{l}\text { PC } 2 \text { Socio- } \\
\text { economic } \\
\text { status (2) }\end{array}$ & $\begin{array}{l}\text { PC } 3 \text { Urban- } \\
\text { isation (1) }\end{array}$ & $\begin{array}{l}\text { PC } 4 \text { Urban- } \\
\text { isation (2) }\end{array}$ & PC 5 & PC 6 & PC 7 \\
\hline PondSize & -.121 & .073 & -.164 & .622 & -.108 & .403 & .064 \\
\hline DetachedPerc & -.246 & .593 & -.014 & .520 & -.226 & .033 & .067 \\
\hline RowHousePerc & -.063 & .084 & -.103 & .034 & -.104 & -.772 & .137 \\
\hline ApartmentPerc & .089 & -.090 & .458 & -.164 & .329 & .276 & .531 \\
\hline OtherHousPerc & .007 & -.127 & -.089 & .640 & .155 & -.072 & -.035 \\
\hline CommBuildPerc & .037 & .100 & .067 & -.035 & .845 & .058 & .159 \\
\hline IndustryBPerc & .227 & .067 & .033 & -.007 & .674 & .003 & -.025 \\
\hline OtherBuildPerc & -.220 & .139 & -.018 & .515 & .375 & -.485 & -.217 \\
\hline PercLakes & -.364 & .143 & -.455 & .019 & .061 & .453 & .150 \\
\hline AllBuildPerc & -.092 & .263 & .835 & -.176 & .106 & -.008 & -.250 \\
\hline Residents & .112 & -.098 & .831 & -.125 & .031 & .059 & .045 \\
\hline VisMinPerc & .123 & -.146 & .278 & -.094 & -.022 & .183 & -.749 \\
\hline LowEduPerc & .416 & .788 & .117 & .070 & .179 & -.106 & .074 \\
\hline HighEduPerc & -.814 & -.305 & .103 & .081 & .044 & .121 & -.090 \\
\hline RelPoorPerc & .246 & .845 & -.090 & -.212 & .145 & -.032 & .076 \\
\hline RelRichPerc & -.583 & -.525 & -.157 & .244 & -.378 & -.048 & .117 \\
\hline SocHelpPerc & .741 & .035 & .089 & -.005 & .206 & .083 & -.278 \\
\hline DistHighway & .583 & .179 & .234 & .089 & .213 & .199 & .367 \\
\hline DistTrain & .129 & -.064 & -.150 & .671 & -.365 & -.177 & .126 \\
\hline
\end{tabular}


Table 3 Results of the PCA of the variables for $500 \mathrm{~m}$ radius around the pond. In bold: factor loading at least 0.5

\begin{tabular}{|c|c|c|c|c|c|c|c|}
\hline \multirow[t]{2}{*}{ Variables } & \multicolumn{7}{|c|}{ Components and their interpretation } \\
\hline & $\begin{array}{l}\text { PC 1 Socio- } \\
\text { economic } \\
\text { status }\end{array}$ & $\begin{array}{l}\text { PC } 2 \\
\text { Urban- } \\
\text { isation (1) }\end{array}$ & $\begin{array}{l}\text { PC } 3 \\
\text { Urban- } \\
\text { isation (2) }\end{array}$ & $\begin{array}{l}\text { PC } 4 \\
\text { Urbanisation \& } \\
\text { Soc-eco. status }\end{array}$ & PC 5 & PC 6 & PC 7 \\
\hline PondSize & .035 & .026 & .171 & .044 & .834 & -.007 & .043 \\
\hline DetachedPerc & -.149 & -.110 & .138 & -.026 & .498 & .632 & .232 \\
\hline RowHousePerc & -.083 & -.044 & .293 & -.009 & -.149 & .170 & .716 \\
\hline ApartmentPerc & .346 & .791 & -.080 & -.013 & -.054 & .188 & -.131 \\
\hline OtherHousPerc & .036 & .070 & .828 & -.096 & .051 & .016 & .014 \\
\hline CommBuildPerc & -.015 & .688 & .123 & .049 & -.142 & .230 & -.394 \\
\hline IndustryBPerc & -.048 & .105 & -.107 & .922 & .036 & .057 & .061 \\
\hline OtherBuildPerc & .074 & -.184 & .809 & .074 & .011 & .167 & .123 \\
\hline PercLakes & -.143 & -.068 & -.043 & -.160 & .695 & -.035 & -.344 \\
\hline AllBuildPerc & .178 & .878 & -.044 & .038 & .060 & .015 & .171 \\
\hline Residents & .067 & .893 & -.146 & .071 & -.016 & -.026 & .039 \\
\hline VisMinPerc & .858 & .215 & -.111 & -.108 & .064 & -.191 & .216 \\
\hline LowEduPerc & .501 & -.047 & .014 & .716 & -.071 & -.088 & -.069 \\
\hline HighEduPerc & -.596 & -.066 & -.251 & -.579 & .241 & .100 & .092 \\
\hline RelPoorPerc & .827 & -.102 & .086 & .126 & -.102 & .080 & -.363 \\
\hline RelRichPerc & -.763 & -.269 & -.075 & -.367 & .221 & -.013 & .194 \\
\hline SocHelpPerc & .885 & .314 & -.058 & .063 & .052 & .025 & .120 \\
\hline DistHighway & -.009 & .301 & .003 & -.010 & -.151 & .797 & .033 \\
\hline DistTrain & -.170 & -.130 & .616 & .011 & .387 & -.255 & .219 \\
\hline
\end{tabular}

At a radius of $800 \mathrm{~m}$ :

- $\quad$ PC1 (32.8\% variance explained) was positively associated with percentage of visible minority, percentage of people getting social help and percentage of relatively low educated and poor people, while negatively associated with percentage of relatively high educated and rich people;

- PC2 (13.6\%) was positively associated with apartment buildings, community buildings, total buildings, and number of residents;

- PC3 (10.5\%) was positively associated with other houses and buildings.

PC4, PC5 and PC6 explained relatively little of the variance (7.3, 5.7 and 5\% respectively) and were not included in further analysis.

In summary, PC1 and PC2 at a radius of $200 \mathrm{~m}$ and PC 1 at radii of 500 and $800 \mathrm{~m}$ were associated with education, residents' level of wealth and social help they were getting. Henceforth, these PCs will jointly be referred to as "socio-economic status" PCs. The remaining PCs described above were associated with amount of residents, density of buildings, and particular types of buildings and will hereafter be encompassed by the term "urbanisation" PCs. An exception was PC4 at a radius of $500 \mathrm{~m}$, which was associated with both urbanisation (industry buildings) and socio-economic status (education).

\section{Species richness}

The ponds differed with regard to amount of species present, ranging from only 1 (two ponds) to as many as 22 (two ponds) species. These numbers ranged from 0 to 10 for Odonata, 0 to 15 for Coleoptera, 0 to 6 for Hemiptera, and 0 to 8 for Trichoptera. On average 9.8 species were present in a pond (median 9.42); 2.3 of Odonata, 4.2 of Coleoptera, 1.3 of Hemiptera, and 2.1 of Trichoptera.

When we regressed species richness on the PCA scores, the overall species richness was negatively associated with the PCs linked to urbanisation factors, such as amount of buildings and number of residents (PC3 for $200 \mathrm{~m}$ and PC2 for 500 and $800 \mathrm{~m}$ : Table 5), meaning that the more buildings or residents, the lower the species richness. For the 500 and $800 \mathrm{~m}$ buffer zone, the overall species richness was negatively associated with the PC2 (Online Resource 2: Tables 1 and 2), linked to the type of buildings, such that species richness was lower with greater numbers of apartments and community buildings there were. When we correlated richness of Odonata with the PCs associated with impervious surfaces, we found the same results as in the case of overall species richness, i.e. amount of residents and buildings were negatively correlated with Odonata richness $(t=-2.373, P=0.024 ; t=-2.830, P=0.007$; 
Table 4 Results of the PCA of the variables for $800 \mathrm{~m}$ radius around the pond. In bold: factor loading at least 0.5

\begin{tabular}{|c|c|c|c|c|c|c|}
\hline \multirow[t]{2}{*}{ Variables } & \multicolumn{6}{|c|}{ Components and their interpretation } \\
\hline & $\begin{array}{l}\text { PC } 1 \text { Socio- } \\
\text { economic status }\end{array}$ & $\begin{array}{l}\text { PC } 2 \text { Urban- } \\
\text { isation (1) }\end{array}$ & $\begin{array}{l}\text { PC } 3 \text { Urban- } \\
\text { isation (2) }\end{array}$ & PC 4 & PC 5 & PC 6 \\
\hline PondSize & .039 & -.047 & .158 & .177 & .846 & .064 \\
\hline BuildingsAge & .133 & -.267 & .106 & .683 & -.010 & .137 \\
\hline DetachedPerc & -.194 & .028 & .157 & .069 & .316 & .774 \\
\hline RowHousePerc & -.036 & -.235 & .230 & .389 & -.119 & .438 \\
\hline ApartmentPerc & .362 & .823 & -.071 & -.079 & .026 & .035 \\
\hline OtherHousPerc & .108 & .031 & .852 & -.048 & .059 & -.053 \\
\hline CommBuildPerc & .142 & .721 & -.041 & -.300 & .003 & .018 \\
\hline IndustryBPerc & .263 & .313 & -.013 & .614 & .014 & -.185 \\
\hline OtherBuildPerc & -.008 & -.035 & .835 & .192 & .032 & .212 \\
\hline PercLakes & -.215 & -.040 & -.015 & -.265 & .761 & -.042 \\
\hline AllBuildPerc & .226 & .845 & .113 & .261 & -.026 & .134 \\
\hline Residents & .143 & .866 & -.050 & .044 & -.072 & .050 \\
\hline VisMinPerc & .923 & .050 & -.066 & .035 & .019 & -.175 \\
\hline LowEduPerc & .869 & .226 & .085 & .346 & -.089 & .005 \\
\hline HighEduPerc & -.629 & -.363 & -.346 & -.349 & .248 & -.019 \\
\hline RelPoorPerc & .901 & -.043 & -.022 & -.087 & .009 & .153 \\
\hline RelRichPerc & -.832 & -.447 & -.154 & -.003 & .150 & .008 \\
\hline SocHelpPerc & .769 & .295 & -.066 & .338 & .022 & -.025 \\
\hline DispIncome & -.693 & -.345 & -.171 & -.028 & .177 & .346 \\
\hline DistHighway & .088 & .348 & -.031 & -.108 & -.205 & .731 \\
\hline DistTrain & .012 & -.464 & .466 & .041 & .267 & .080 \\
\hline
\end{tabular}

$t=-3.467, P=0.001$; for 200,500 and $800 \mathrm{~m}$ respectively, See Online Resource 3: Tables 1-3). However, for the other three groups we found less significant relationships, but there was a negative association with amount of residents and buildings at the $500 \mathrm{~m}$ scale for Coleoptera and at the $800 \mathrm{~m}$ scale for Trichoptera (see Online Resource 3: Tables 5 and 12). Interestingly, richness of Hemiptera showed a significant positive relationship with PC1 (Online Resource 3: Table 9). In summary, total richness was negatively associated with amount of buildings and number of residents. A similar patterns of species richness association was found when the data set was dissected down to the level of insect order, although some of the relationships for the overall data set were none significant for some of the orders.

PCs associated with the socio-economic status of residents, i.e. their level of education or wealth or percentage of visible minority (PC 1 and 2 for $200 \mathrm{~m}$, PC 1 and 4 for $500 \mathrm{~m}$, and PC 1 for $800 \mathrm{~m}$ ) did not show a significant relationship with overall species richness (Table 5; Online Resource 2: Tables 1 and 2) or richness of particular taxonomic groups. The only significant results was revealed for Hemiptera that at the scale of $800 \mathrm{~m}$ was correlated with PC 1, associated with socio-economic factors linked to education and economic wealth (See Online resource 3: Table 9).
Table 5 Results of PCA regression for $200 \mathrm{~m}$ radius for overall species richness. $\mathrm{R}^{2}=0.317$; total $\mathrm{df}=36 ; n=51$. In bold: significant effect with $p<0.05$

\begin{tabular}{|c|c|c|c|c|c|}
\hline \multirow[t]{2}{*}{ Model } & \multicolumn{2}{|c|}{ Unstandardized Coefficients } & \multicolumn{2}{|c|}{ Standardized Coefficients } & \multirow[t]{2}{*}{$\mathrm{P}$} \\
\hline & $\mathrm{B}$ & Std. Error & Beta & $\mathrm{t}$ & \\
\hline (Constant) & 9.486 & .797 & & 11.898 & .000 \\
\hline PC 1 & -.227 & .808 & -.043 & -.281 & .781 \\
\hline $\mathrm{PC} 2$ & -.941 & .808 & -.179 & -1164 & .254 \\
\hline PC 3 & -2.181 & .808 & -.414 & -2.698 & .012 \\
\hline $\mathrm{PC} 4$ & .830 & .808 & .158 & 1027 & .313 \\
\hline
\end{tabular}




\section{Shannon-Wiener index and evenness}

When biodiversity was estimated as Shannon Wiener index we found the same pattern for the whole data set as for species richness, i.e. it there was a negative relationship between the index and the amount of buildings and number of residents (Online Resource 4: Tables 1-3). For evenness we found only one significant relationship and that was positive relationship between evenness and PC4 at a scale of 800 (Online Resource 4: Table 6). However, PC4 explained only $7 \%$ of the variation.

\section{Discussion}

Our study found that biodiversity of aquatic insects was significantly negatively associated with the PCs linked to urbanisation, i.e. the ones associated with amount of buildings and of residents living around the pond. This relation was valid at all three scales of buffer zones investigated. In addition, we found that biodiversity was also negatively associated with the PC linked to percentage of apartments and community buildings within the $500 \mathrm{~m}$ buffer zone, which may be perhaps explained by the fact that such buildings usually have more residents than other types of buildings (e.g. detached or row houses). These relations were valid for overall biodiversity and also to some degree at level of insect order. This result is in line with other studies that have found that amount of build-up areas and related fragmentation of habitats is the main reason for the loss of biodiversity in cities. These studies have, for example, found that increased urbanisation was negatively associated with butterflyspecies richness (Clark et al. 2007), and amphibian assemblages (Parris 2006). McKinney (2008) who reviewed over 100 studies on the impact of urbanisation on species richness confirmed this trend for different taxa. The same logic seems to apply to urban ponds, as our results indicate. The lower richness of species in areas with more impervious surfaces (e.g. more buildings and thus potentially less green areas) may be related to the low connectivity between habitats, affecting species dispersal between habitats (Damschen and Brudwig 2012; Chester and Robson 2013; Guimarães et al. 2014). Similarly, the impact of more impervious surfaces on reducing connectivity in our study, is probably one of the reasons for the lower species richness of areas with more apartments and community buildings. However, there is a need for more in-depth investigation of the impacts of impervious surfaces on biodiversity, since surfaces may act very differently, depending on species group. It also needs to be underlined that our study is of exploratory character where we included many different variables to shed a light on broad patterns between biodiversity and socio-economic factors. We acknowledge that it was not a focus of the study to investigate the potential differences between different types of ponds or consider pond density. However, such studies would be an important continuation of the analysis initiated in the present paper.
Although it was not the purpose of our study, future studies on urban ponds should focus on the relation between connectivity patterns and species richness in urban ponds. For example, in stream ecology, the so called urban stream syndrome has gained much research interest in the past 15 years (Paul and Meyer 2001; Meyer et al. 2005; Walsh et al. 2005; Hughes et al. 2014). This concept identifies a number of factors that affect urban watercourses that lead to reductions in biodiversity and dominance of tolerant species: increases in water-level fluctuation, nutrients, pollutants, temperature, and canalisation (Walsh et al. 2005). These factors increase with the proportion of impervious surface in the catchment. Thus, connectivity provided by watercourses may have a negative effect on biodiversity in highly-developed catchments with a high percentage of impervious surface. In contrast, connectivity facilitated by vegetated terrestrial habitats may be positive, at least for insect with aerial life stages (Braaker et al. 2014).

We found no significant relationships between the different socio-economic variables and species richness in ponds. In contrast, many other studies investigating the relationship between biodiversity in cities and species richness of taxa, such as birds or plants (Iversson and Cook 2000; Hope et al. 2003; Melles 2005; Loss et al. 2009), have found a correlation between socio-economic status and species richness. Some of these effects were explained by the so called "luxury effect" where people with higher socio-economic status have more possibilities to influence their nearby environment, particularly when the presence of species depends on human choices and landscape maintenance (Martin et al. 2003), or by "legacy effect" where neighbourhood green areas vegetation may depend on development time (Cook et al. 2012). Other studies underlined role of human behaviour in management decisions and the importance of social norms (Troy et al. 2007; Locke and Grove 2016). In relation to urban ponds, Blicharska et al. (2016) investigated the potential connection between the types of ponds and level of management (as described by pond managers), and biodiversity of urban ponds, however, they did not find significant relationship between these variables and species richness in ponds. Nevertheless, the authors acknowledged that more detailed analysis, including actual measurement of management intensity would be needed.

Without more data and detailed analysis of such data, it is difficult to explain why we did not find a relationship between biodiversity and socioeconomic factors in the city of Stockholm. Gledhill and James (2012) suggest that, while it is unlikely that socio-economic status of residents directly influences species occurrence, some physical features of particular areas related to their socio-economic status may influence pond ecology. For instance, one could hypothesise that although richer and poorer areas are of different character and provide various conditions for biodiversity, they may have similar levels of biodiversity due to different mechanisms. For example, richer areas might contain more green areas (Iversson and Cook 2000; 
Kinzig et al. 2005) and, thus, include more ponds and that could provide better connectivity and higher potential for biodiversity. On the other hand, richer areas with more detached and semidetached houses might have more impervious surfaces (e.g. increased amount of parking lots) (Perry and Nawaz 2008), or more intensively-managed ponds without vegetation, which could lead to less biodiversity. At the same time, poorer areas could be less cared for and managed and, thus, support more natural and abundant vegetation, leading to levels of biodiversity comparable to the biodiversity of richer areas (although for different reasons). Hence, there is a need for a finer-scale investigation of the different ways that residents in areas with differing socio-economic status might indirectly influence ponds. As Gledhill and James (2012) conclude "Clearly the connection between social classification and pond ecology is complex and requires a greater understanding of the precise physical, as well as social nature of development surrounding particular ponds".

Interestingly, we found some differences among our insect orders in the relationship between the amount of buildings and of residents living around the pond and species richness. While Odonata showed the same patterns as the overall dataset, Trichoptera and Coleoptera showed it only at a certain scale, 500 and $800 \mathrm{~m}$ radius scale respectively. For Hemiptera no pattern was found with respect to these environmental variables. Interesting, Goertzen and Suhling (2013) found no strong effect on land use variables around city ponds in their study on biodiversity of Odonata when using a radius of $500 \mathrm{~m}$. Nevertheless, the insect order and scale differences, could be related to dispersal and or niche specialisation. In general, we would expect species with high dispersal and a general niche to be affected at larger scales, compared to those with limited dispersal and a more specialised niche (Concepción et al. 2015). Information on dispersal abilities in our insect taxa is limited, and therefore an analyses including some kind of dispersal variable would be very weak. Size has been used as a surrogate for studying dispersal in insects, but shows not consistence between studies with regard to dispersal (De Bie et al. 2012). We note that the Odonata, which are believed to be strong flyers with good dispersal abilities (Corbet 1999), showed effects of urbanisation at all three scales, suggesting that dispersal does not affect the results of this order at the level of these scales. As for dispersal, we have no or little information on niche use in our species, but we encourage studies using dispersal and niche use differences among species to unravel differences in urbanisation in relation to these two variables.

Two of our biodiversity indexes, richness and Shannon Wiener show a negative relationship with regard to the PCs that described the amount of buildings and of residents living around the pond. These two indexes which have a focus on species number per see, thus gave the same results with regard to biodiversity. In contrast, evenness, which reflects abundance distribution of species (a high evenness suggest similar frequencies of the species in the sample), showed no relationship with these environmental variables. This suggest that although, for example, species richness decrease with amount of buildings, for those species that are present, the proportion among them is similar as one moves along the environmental gradient. Other studies have also found that species richness and evenness do not show similar response to urbanisation. For example Rota et al. (2015) found that taxonomic richness of soil fauna increased with distance from roads whereas evenness showed higher values at both ends of the gradient. Similarly, Turrini and Knop (2015), found in a study of six cities, that a high amount of vegetated area in the cities increased species richness and abundance of the majority of investigated arthropod groups, whereas evenness showed no clear pattern within cities.

In our study, we utilized three different scales of buffer zones in analysis, since results in landscape ecology studies are affected by the spatial scale of the study (Wu et al. 2002). For example, a study by Andersson et al. (2009) conducted in Stockholm investigated whether scale chosen for analysis influenced relationships between landscape variables and urbanization patterns. The authors concluded that correlations between some variables may change depending on the scale used, while others will remain unchanged and hence there is a need for use of multi-scaled gradients. Our results, however, were broadly similar across all three sizes of buffer zones (200, 500, and $800 \mathrm{~m}$ radius) when we used all insect taxa, suggesting that at this scale the patterns we found are robust.

\section{Conclusions}

To conclude, our results suggest no strong relationship between biodiversity of city ponds and socioeconomic factors in the city of Stockholm. This results contrast with those found for terrestrial environments where higher biodiversity has been found in areas with higher socio-economic status (Iversson and Cook 2000; Hope et al. 2003; Melles 2005). We suggest that this difference between aquatic and terrestrial environment could be due to two main factors. First, it could be that terrestrial and aquatic environments are affected differently by socioeconomic factors with regard to biodiversity. Second, it could be an effect of difference in methods used to investigate the biodiversity. Future studies are needed to investigate in detail in what way the socioeconomic factors could influence biodiversity in terrestrial and aquatic environments in the cities. These studies should use as similar methods as possible and there is a need for comparative studies in the same geographic area.

Acknowledgements We would like to thank Claudia von Brömssen and Per-Ola Hedwall for help with statistics and Richard Smithers for language editing. This work was financed by Swedish Biodiversity Centre and Uppsala University. 
Open Access This article is distributed under the terms of the Creative Commons Attribution 4.0 International License (http:// creativecommons.org/licenses/by/4.0/), which permits unrestricted use, distribution, and reproduction in any medium, provided you give appropriate credit to the original author(s) and the source, provide a link to the Creative Commons license, and indicate if changes were made.

\section{References}

Andersson E, Ahrné K, Pyykönen M, Elmqvist T (2009) Patterns and scale relations among urbanization measures in Stockholm, Sweden. Landsc Ecol 24:1331-1339

Biggs J, Williams P, Whitfield M, Nicolet P, Weatherby A (2005) 15 years of pond assessment in Britain: results and lessons learned from the work of pond conservation. Aquat Conserv Mar Freshwat Ecosyst 15:693-714

Blicharska M, Johansson F (2016). Urban ponds for people and by people. In: Francis R, Millington J, Chadwick MA (eds) Urban landscape ecology: science, policy and practice. Routledge, pp. 164-180

Blicharska M, Andersson J, Bergsten J, Bjelke U, Hilding-Rydevik T, Johansson F (2016) Effects of management, function and vegetation on the biodiversity in urban ponds. Urban For Urban Gree 20:103-112

Braaker S, Ghazoul J, Obrist MK, Moretti M (2014) Habitat connectivity shapes urban arthropod communities - the key role of green roofs. Ecology 95:1010-1021

Céréghino R, Biggs J, Oertli B, Declerck S (2008) The ecology of European ponds: defining the characteristics of a neglected freshwater habitat. Hydrobiologia 597:1-6

Chester ET, Robson BJ (2013) Anthropogenic refuges for freshwater biodiversity: their ecological characteristics and management. Biol Conserv 166:64-75

Clark PJ, Reed JM, Chew FS (2007) Effects of urbanization on butterfly species richness, guild structure, and rarity. Urban Ecosystems 10: 321-337

Colding J, Lundberg J, Lundberg S, Andersson E (2009) Golf courses and wetland Fauna. Ecol Appl 19:1481-1491

Concepción ED, Moretti M, Altermatt F, Nobis MP, Obrist MK (2015) Impacts of urbanisation on biodiversity: the role of species mobility, degree of specialisation and spatial scale. Oikos 214:1571-1582

Cook EM, Hall SJ, Larson KL (2012) Residential landscapes as socialecological systems: a synthesis of multi-scalar interactions between people and their home environment. Urban Ecosystems 15:19-52

Corbet P (1999) Dragonflies: behavior and ecology of Odonata. Harley Books, Colchester

Damschen EI, Brudwig LA (2012) Landscape connectivity strengthens local-regional richness relationships in successional plant communities. Ecology 93:704-710

Davies B, Biggs J, Williams P, Whitfield M, Nicolet P, Sear D, Bray S, Maund S (2008) Comparative biodiversity of aquatic habitats in the European agricultural landscape. Agric Ecosyst Environ 125:1-8

De Bie T et al (2012) Body size and dispersal mode as key traits determining metacommunity structure of aquatic organisms. Ecol Lett 15:740-747

Fischel WA (1985) The economics of zoning laws: a property rights approach to American land use controls. John Hopkins University Press, Baltimore

Gaston KJ, Smith RM, Thompson K, Warren PH (2004) Gardens and wildlife: the BUGS project. British Wildlife 16:1-9

Gaston KJ, Warren PH, Thompson K, Smith RM (2005) Urban domestic gardens (IV): the extent of the resource and its associated features. Biodivers Conserv 14:3327-3349
Gledhill DG, James P (2012) Socio-economic variables as indicators of pond conservation in an urban landscape. Urban Ecosyst 15:849-861

Gledhill DG, James P, Davies DH (2005) Urban pond: a landscape of multiple meanings. Paper presented at the 5 th international postgraduate research conference in the built and human environment. University of Salford, UK

Goertzen D, Suhling F (2013) Promoting dragonfly diversity in cities: major determinants and implications for urban pond design. J Insect Conserv 17:299-399

Grove JM, Troy AR, O'Neil-Dunne JPM, Burch WR, Cadenasso ML, Pickett STA (2006) Characterization of households and its implications for the vegetation of urban ecosystems. Ecosystems 9:578-597

Guimarães TFR, Hartz SM, Becker FG (2014) Lake connectivity and fish species richness in southern Brazilian coastal lakes. Hydrobiologia 740:207-217

Hassall C, Anderson S (2015) Stormwater ponds can contain comparable biodiversity to unmanaged wetlands in urban areas. Hydrobiologia 745:137-149

Hassall C, Hollinshead J, Hull A (2011) Environmental correlates of plant and invertebrate species richness in ponds. Biodivers Conserv 20: 3189-3222

Hill MJ, Wood PJ (2014) The macroinvertebrate biodiversity and conservation value of garden and field ponds along a rural-urban gradient. Fundam Appl Limnol 185:107-119

Hope D, Gries C, Zhu W, Fagan WF, Redman CL, Grimm NB, Nelson AL, Martin C, Kinzig A (2003) Socioeconomics drive urban plant diversity. PNAS 100:8788-8792

Hughes RM, Dunham S, Maas-Hebner KG, Yeakley JA, Schreck C, Harte M, Molina N, Shock CC, Kaczynski VW, Schaeffer J (2014) A review of urban water body challenges and approaches: (1) rehabilitation and remediation. Fisheries 39:18-29

Iversson LR, Cook EA (2000) Urban forest cover of the Chicago region and its relation to household density and income. Urban Ecosystems 4:105-124

Johansson M, Hartig T, Staats H (2011) Psychological benefits of walking: moderation by company and outdoor environment. Appl Psychol 3:261-280

Kadoya T, Suda S, Washitani I (2004) Dragonfly species richness on man-made ponds: effects of pond size and pond age on newly established assemblages. Ecol Res 19:461-467

Kinzig AP, Warren P, Martin C, Hope D, Katti M (2005) The effects of human socioeconomic status and cultural characteristics on urban patterns of biodiversity. Ecol Soc 10:23

Krebs, C.J. (1989) Ecological methodology. Harper and Row, New York. pp. 654

Landry SM, Chakraborty J (2009) Street trees and equity: evaluating the spatial distribution of an urban amenity. Environ Plan A 41:2651-2670

Le Viol I, Mocq J, Julliard R, Kerbiriou C (2009) The contribution of motorway stormwater retention ponds to the biodiversity of aquatic macroinvertebrates. Biol Conserv 142:3163-3171

Locke DH, Grove JM (2016) Doing the hard work where it's easiest? Examining the relationships between urban greening programs and social and ecological characteristics. Appl Spatial Anal Policy 9:77-96

Loram A, Warren P, Thompson K, Gaston K (2011) Urban domestic gardens: the effects of human interventions on garden composition. Environ Manag 48:808-824

Loss SR, Ruiz MO, Brawn JD (2009) Relationships between avian diversity, neighborhood age, income, and environmental characteristics of an urban landscape. Biol Conserv 142(11):2578-2585

Luck GW, Smallbone LT, O'Brien R (2009) Socio-economics and vegetation change in urban ecosystems: patterns in space and time. Ecosystems 12:604-620 
MacArthur RH, Wilson EO (1967) The theory of island biogeography. Princeton University Press, Princeton, New Jersey

Martin CA, Peterson KA, Stabler LB (2003) Residential landscaping in Pheonix, Arizona, U.S.: practices to covenants, codes and restrictions. J Arboric 29:9-17

Martin CA, Warren PS, Kinzig AP (2004) Neighborhood socioeconomic status is a useful predictor of perennial landscape vegetation in residential neighborhoods and embedded small parks of Phoenix, AZ. Landsc Urban Plan 69:355-368

McKinney ML (2008) Effects of urbanisation on species richness: a review of plants and animals. Urban Ecosystems 11:161-176

Melles SJ (2005) Urban bird diversity as an indicator of human social diversity and economic inequality in Vancouver, British Columbia. Urban Habitats 3:25-48

Meyer JL, Paul MJ, Taulbee WK (2005) Stream ecosystem function in urbanizing landscapes. J N Am Benthol Soc 24:602-612

Nassauer JI, Wang Z, Dayrell E (2009) What will the neighbors think? Cultural norms and ecological design. Landsc Urban Plan 92:282-292

O'Brien CD (2015) Sustainable drainage system (SuDS) ponds in inverness, UK and the favourable conservation status of amphibians. Urban Ecosystems 18:321-331

Oertli B, Joye DA, Castella E, Juge R, Cambin D, Lachavanne JB (2002) Does size matter? The relationship between pond area and biodiversity. Biol Conserv 104:59-70

Oertli B, Céréghino R, Biggs J, Declerck S, Hull AP, Miracle MR (2010) Pond conservation in Europe. Developments in hydrobiology Vol. 210. Spinger Verlag

Parris KM (2006) Urban amphibian assemblages as metacommunities. J Anim Ecol 75:757-764

Paul M, Meyer J (2001) Riverine ecosystems in an urban landscape. Annu Rev Ecol Syst 32:333-365
Perry T, Nawaz R (2008) An investigation into the extent and impacts of hard surfacing of domestic gardens in an area of Leeds, United Kingdom. Landsc Urban Plan 86:1-13

Pond Conservation (2002) A guide to monitor the ecological quality of ponds and canals using PSYM. Oxford Brookes University, Pond conservation Trust, UK

Rota E, Caruso T, Migliorini M, Monaci F, Agamennone V, Biagini G, Bargagli R (2015) Diversity and abundance of soil arthropods in urban and suburban holm oak stands. Urban Ecosystem 18:715-728

SCB (2015) http://www.scb.se/en /Services/Guidance-for-researchersand-universities/SCB-Data/Longitudinal-integration-database-forhealth-insurance-and-labour-market-studies-LISA-by-Swedishacronym/ Accessed 2015-08-30

SEPA (Swedish Environmental Protection Agency) (2006) Bottenfauna i sjöars litoral och vattendrag. SS-EN 27828

Smith RM, Gaston KJ, Warren PH, Thompson K (2005) Urban domestic gardens (V): relationships between landcover composition, housing and landscape. Landsc Ecol 20:235-253

Tratalos J, Fuller RA, Warren PH, Davies RG, Gaston KJ (2007) Urban form, biodiversity potential and ecosystem services. Landsc Urban Plan 83:308-317

Troy AR, Grove JM, O’Neil-Dunne JPM, Pickett S, Cadenasso ML (2007) Predicting opportunities for greening and patterns of vegetation on private urban lands. Environ Manag 40:394-412

Turrini T, Knop E (2015) A landscape ecology approach identifies important drivers of urban biodiversity. Glob Chang Biol 21: 1652-1667

Walsh CJ, Roy AH, Feminella JW, Cottingham PD, Groffman PM, Morgan RP (2005) The urban stream syndrome: current knowledge and the search for a cure. J N Am Benthol Soc 24:706-723

Wu J, Shen W, Sun W, Tueller PT (2002) Empirical patterns of the effects of changing scale on landscape metrics. Landsc Ecol 17:761-782 